\title{
Urban Populations of Aedes aegypti (Diptera: Culicidae) From Central Argentina: Dispersal Patterns Assessed by Bayesian and Multivariate Methods
}

\author{
Ana María Ayala, ${ }^{1,2,4}$ Noelia Soledad Vera, ${ }^{1}$ Marina Beatriz Chiappero, ${ }^{1,2}$ \\ Walter Ricardo Almirón, ${ }^{3}$ and Cristina Noemí Gardenal ${ }^{2}$
}

\begin{abstract}
'Universidad Nacional de Córdoba, Facultad de Ciencias Exactas, Físicas y Naturales. Cátedra de Genética de Poblaciones y Evolución, Córdoba, Argentina, ${ }^{2}$ Instituto de Diversidad y Ecología Animal, Consejo Nacional de Investigaciones Científicas y Técnicas (IDEA, CONICET), Córdoba, Argentina, ${ }^{3}$ Centro de Investigaciones Entomológicas de Córdoba-Instituto de Investigaciones Biológicas y Tecnológicas (CIEC-IIByT), CONICET- Universidad Nacional de Córdoba, Argentina, and ${ }^{4}$ Corresponding author, e-mail: aneta_ay@hotmail.com
\end{abstract}

Subject Editor: Michel Slotmans

Received 2 August 2019; Editorial decision 15 January 2020

\begin{abstract}
Aedes aegypti (L.), the main vector of dengue and other arboviruses, was declared eradicated from Argentina in 1964; however, in 1987, it was detected again and nowadays it occurs in most of the country territory. To understand the transmission of vector-borne diseases, knowledge of the dispersal of vector populations is essential to evaluate the risk of pathogen transmission. We conducted a population genetic analysis of $A e$. aegypti in 20 neighborhoods from Córdoba, the second largest city in Argentina, using 10 microsatellite loci. High genetic differentiation and the absence of an isolation by distance pattern was found using Weir and Cockerham's $\theta$. Bayesian and multivariate clustering analyses showed that the studied sites included individuals with high membership coefficients $(Q)$ in their populations, individuals with membership in another cluster, and admixed individuals. Individuals with high $\mathrm{Q}$ in clusters different from the population in which they were collected strongly suggests that passive transport is important in shaping the Ae. aegypti dispersal pattern in Córdoba city. Knowing the genetic structure of Ae. aegypti populations and their dispersal patterns would contribute to the implementation of vector control programs.
\end{abstract}

Key words: Aedes aegypti, microsatellites, population genetic structure, Córdoba city (Argentina)

Aedes aegypti (L.) is a highly domestic and anthropophilic mosquito species native to Africa introduced in the New World by shipping trade routes, most likely during the 17th century (Powell et al. 2018). Females oviposit mostly in artificial containers inside and around human dwellings; therefore, the species' dispersal range is strongly conditioned by both the availability of oviposition sites and blood sources, which contribute to its efficiency as vector of different arboviruses (Gubler 2014). Aedes aegypti is the primary urban vector of several emerging mosquito-borne pathogens throughout all tropical and subtropical areas, with over 3.6 billion people currently living in infested areas (Reiter 2014, Higgs and Vanlandingham 2015). Although dengue is the most common virosis transmitted by this mosquito, in recent years, other arboviruses such as zika and chikungunya have spread rapidly in the Americas, also gaining epidemiological relevance (Mayer et al. 2017).

In the 1940s, the Pan American Health Organization initiated an Ae. aegypti eradication program, which resulted in its elimination from 19 countries (Gubler 2014). Unfortunately, in Argentina, this mosquito was probably never fully eliminated (Rondan Dueñas et al. 2009), and in 1987, the vector was detected in the north of the country (Curto et al. 2002). The expansion continued in the subsequent years (Schweigmann and Boffi 1998), and nowadays, the species occurs in most Argentine provinces (Domínguez and Lagos 2001, Grech et al. 2012, Zanotti et al. 2015, Díaz Nieto et al. 2016). In mosquito-borne diseases, the levels and patterns of transmission among human populations are determined by multiple and complex factors; for this reason, vector control remains to be one of the most viable strategies to prevent epidemics (Gubler 2014). To evaluate the risk of pathogen transfer and to develop effective control strategies, knowledge of the dispersal patterns of vector populations is essential (McCoy 2008). Using mark-releaserecapture methods, it was found that individuals of this species typically fly only a few hundred meters (Gubler 2014). While these methods are a direct way of measuring Ae. aegypti movement 
distances because they involve tracking individual organisms, they do not quantify effective dispersal, i.e., they do not reflect the levels of gene flow, which depend on the reproductive success of migrants in the receiving population (Broquet and Petit 2009). Data obtained from highly variable loci provide knowledge of the distribution of genetic variation among populations; thus, more accurate inferences of effective dispersal can be made and, therefore, the genetic relationships and patterns of gene flow among populations can be assessed.

Throughout the world, the genetic structure of Ae. aegypti populations was estimated at different spatial scales, using different molecular markers. In Argentina, the first estimates of the species' genetic structure after its reemergence were made by de Sousa et al. (2001) using Random Amplified Polymorphic DNA markers (RAPDs). They found significant genetic differentiation among populations from central and northern Argentina. In later phylogeographic studies based on three mitochondrial genes, the coexistence of three divergent haplogroups with a well-defined geographical distribution was reported. This pattern would have resulted from the persistence of relictual populations that had not been eradicated by the continental control campaign, combined with multiple introductions of different lineages of the species from neighboring countries, probably facilitated by passive transport (Rondan Dueñas et al. 2009; Albrieu Llinás and Gardenal 2011, 2012). Soliani et al. (2010) suggested passive transport of larvae and eggs from Argentina as the main origin source of populations of Uruguay.

Given the anthropophilic habits of the species and its short flight range, many studies of small-scale genetic structure have been conducted within cities around the world (e.g., Huber et al. 2002, Mousson et al. 2002, da Costa-Fraga et al. 2003, Endersby et al. 2011). In Argentina, the only study of Ae. aegypti genetic structure at micro-geographical scale was carried out by Julio et al. (2009) using Random Amplified Polymorphic DNA markers (RAPDs) in seven neighborhoods from Córdoba city, the second largest metropolitan area in Argentina and an important commercial and industrial center located at the crossroads of many national and international routes. Populations formed three clusters by genetic similarity. Each cluster comprised populations connected by, or near to, main roads. The authors suggested that the observed genetic structure would be determined by a combination of low to moderate levels of gene flow (mediated mainly by passive transport along main roads) and significant genetic drift events every winter that differentiate the populations at random. The authors proposed that a more extensive sampling would be necessary to estimate dispersal levels within the city. In addition, RAPD markers are dominantly inherited (which prevents to estimate mating system), have a low reproducibility (the technique is sensitive to minor changes in reaction conditions), and present problems of co-migration of bands (a visible band may contain amplified fragments of similar molecular weight that differ in nucleotide sequence). Thereby, they are not as efficient as co-dominant markers like microsatellite loci for population genetics studies (Kumar and Gurusubramanian 2011). In the present work, we improved the sampling strategy, molecular markers and statistical methodologies used, to deepen the knowledge of the genetic structure of Ae. aegypti populations from Córdoba. We used several approaches (classical population genetics methods, and Bayesian and multivariate genetic clustering) to estimate the genetic differentiation among 20 neighborhoods and to infer dispersal patters within the city.

\section{Methods}

\section{Study Area and Sample Collection}

Córdoba city $\left(64^{\circ} 12^{\prime} \mathrm{W} 31^{\circ} 22^{\prime} \mathrm{S}\right)$, with a surface area of $576 \mathrm{~km}^{2}$ and about 1.4 million inhabitants, is an important commercial and industrial center located at the crossroads of several national and international routes. The city is surrounded by a beltway and crossed by the Suquía River and one of its tributaries, partially channeled into a waterway (La Cañada creek). The region presents a temperate semidry climate, with a mean annual precipitation of $800 \mathrm{~mm}$ concentrated in the summer, and markedly dry winters.

Samples were obtained from 20 neighborhoods (sampling sites) distributed evenly throughout the city (Fig. 1 and Table 1). In each site, a single household was randomly selected to place a georeferenced ovitrap with the consent of its residents. Each ovitrap was replaced weekly from February to April 2012, yielding 12 ovitraps per sampling site. Ovitraps were transported to the laboratory and the eggs were reared to fourth-instar larvae. A mean of 425 eggs (range 99-1,149) were obtained for each sampling site (Table 1). Twenty larvae per neighborhood were randomly chosen from the pool of fourth-instar larvae obtained for each location and identified according to the key of Rossi and Almirón (2004). Taking into account the 'skip oviposition' behavior of the species (Reiter 2007), this procedure decreases the probability of having full sibs in the analyzed sample.

\section{Molecular Methods and Genotyping}

Genomic DNA was extracted from each larva using the phenolchloroform procedure (Ballinger-Crabtree et al. 1992). The quality of the DNA obtained was analyzed by running a 5- $\mu$ l aliquot on a $1 \%$ agarose gel stained with ethidium bromide. DNA was eluted to a final concentration of $10 \mathrm{ng} / \mu \mathrm{l}$ and stored at $-20^{\circ} \mathrm{C}$.

Ten microsatellite loci (Chambers et al. 2007, Slotman et al. 2007) were amplified by polymerase chain reaction (PCR) using fluorescently labeled forward primers. The PCRs were performed in a total volume of $10 \mu \mathrm{l}$, containing $1 \times$ reaction buffer $(10 \mathrm{mM}$ Tris-HCl, pH 8.8; 50 mM KCl, $0.08 \%$ Nonidet P40), $\mathrm{MgCl}_{2}$ (1.20$1.75 \mathrm{mM}$ depending on each primer, Supp Table 1 [online only]), forward and reverse primers $(0.5 \mu \mathrm{M}$ each $)$, dNTPs $(0.2 \mathrm{mM})$, genomic DNA (10 ng), and $1 \mathrm{U}$ of Taq polymerase (Fermentas Life Sciences). The amplification proceeded through an initial denaturation at $92^{\circ} \mathrm{C}$ for $5 \mathrm{~min}$, followed by 28 cycles of $92^{\circ} \mathrm{C}$ for $30 \mathrm{~s}, 55^{\circ} \mathrm{C}$ for $30 \mathrm{~s}$, $72^{\circ} \mathrm{C}$ for $30 \mathrm{~s}$, and a final extension of $5 \mathrm{~min}$ at $72^{\circ} \mathrm{C}$. The molecular size of the PCR products was determined using an automatic sequencer ABI3730XL (Macrogen Korea).

Fragments were scored using the software Peak Scanner v0.1.1 (Applied Biosystems 2006) and the bin limits of fragment sizes were defined with the program MsatAllele (Alberto 2009).

\section{Genetic Variability and Population Differentiation}

Hardy-Weinberg $(\mathrm{H}-\mathrm{W})$ and linkage equilibrium between pairs of loci were tested using FSTAT (Goudet 2002). Significant deviations from $H-W$ proportions were identified and classified according to whether they were consistent with null alleles, short allele dominance or scoring errors associated with stuttering, using the software Microchecker (van Oosterhout et al. 2004).

Observed and expected heterozygosity $\left(H_{o}\right.$ and $\left.H_{e}\right)$ were calculated using Genalex v0.6.5 (Peakall and Smouse 2012), whereas allelic richness (AR) was assessed applying the rarefaction method of El Mousadik and Petit (1996) with FSTAT. Population genetic structure was examined by means of $F$ statistics using the corrected 


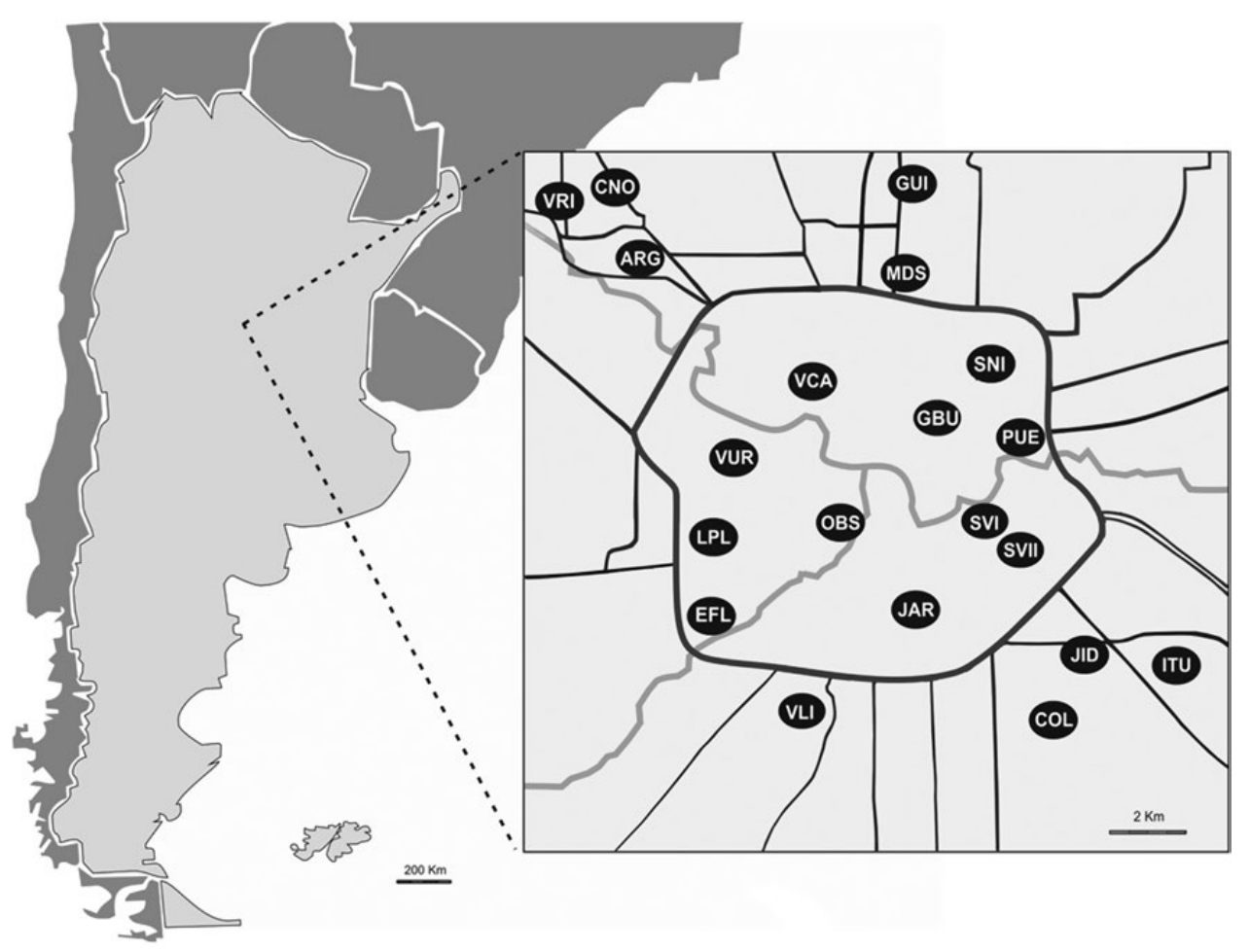

Fig. 1. Geographical location of the 20 neighborhoods in Córdoba city where Aedes aegypti samples were collected in February to April 2012. VCA (Villa Cabrera), ARG (Argüello), VRI (Villa Rivera Indarte), CNO (Cerro Norte), MDS (Marqués de Sobremonte), GUI (Guiñazú), SNI (San Nicolás), PUE (Pueyrredón), SVI (San Vicente I), ITU (Ituzaingó), JID (José Ignacio Díaz), COL (Coronel Olmedo), VLI (Villa EI Libertador), EFL (Estación Flores), VUR (Villa Urquiza), LPL (Los Plátanos), GBU (General Bustos), SVII (San Vicente II), JAR (Jardín), and OBS (Observatorio).

method of Weir and Cockerham (1984), where $\theta$ is an estimator of the parameter $F_{\mathrm{ST}}$ measuring the amount of differentiation among populations, and $f$ estimates $F_{\mathrm{IS}}$, the inbreeding coefficient within subpopulations. Significance of $\theta$ and $f$ was estimated using 200,000 random permutations. Sequential Bonferroni corrections were applied for all multiple tests. Genetic isolation by geographical distance was analyzed via Mantel tests between the linearized genetic distance (calculated as $F_{\mathrm{ST}} J\left(1-F_{\mathrm{ST}}\right)$ according to Rousset (1997)) and the geographical distances between pairs of neighborhoods using the GenalEx program v0.6.5 (Peakall and Smouse 2012). Significance of the correlation was assessed through 9,999 random permutations.

\section{Genetic Clustering by Bayesian and Multivariate Approaches}

The Bayesian clustering method implemented in the program Structure v0.2.3.3 (Pritchard et al. 2000) was used to estimate the most likely number of populations $(K)$ present in the data set. This software uses a Bayesian approach to estimate the most probable number of clusters of individuals, each characterized by their multilocus genotype, by maximizing $H-W$ equilibrium within loci, and gametic phase equilibrium between loci. The inference of ancestry $(Q)$ of each individual to each inferred cluster was assessed using an admixture model (which allows individuals to exhibit ancestry from multiple clusters), with correlated allele frequencies and without prior information of the populations to which the individuals belonged $(\mathrm{POP}=\mathrm{USEPOPINFO}=0)$. Ten independent runs were performed for values of $K$ from 1 to 20. Each run consisted of 5,000,000 MCMC iterations, with a burn-in of 500,000 iterations. The inference of $K$ via the $\Delta K$ statistic (the rate of change of the probability of data as a function of $K$ Evanno et al. 2005) was performed employing Structure Harvester (Earl and Von Holdt 2012).
The outputs of the 10 independent runs for each $K$ were combined using Clumpp (Jakobsson and Rosenberg 2007) and a visual output for the individual cluster coefficients was generated using the program Distruct (Rosenberg 2004).

A discriminant analysis of principal components (DAPC) was applied, using the Adegenet package (Jombart 2008) for R ( $R$ Development Core Team 2007). This multivariate clustering method is based on a discriminant analysis performed on data previously transformed by a principal component analysis. The purpose of this approach was to define groups of genetically similar individuals, by maximizing the intergroup component of the genetic variation. Unlike Bayesian approaches, DAPC does not rely on a particular population genetics model, and is thus free of assumptions about $H$-W or linkage equilibrium. This allows describing complex structures and generating a visual assessment of between-group structures (Jombart et al. 2010). The number of clusters was assessed by running successive $K$-means clustering with increasing number of clusters $(K)$, and applying the Bayesian information criterion (BIC) to assess the best supported $K$-value. DAPC was performed on the PCA transformed data for the optimal $K$-value. The optimal number of PCs to be retained for DAPC clustering was obtained with the function optim.a.score in Adegenet.

\section{Results}

\section{Genetic Variability and $\mathrm{H}-\mathrm{W}$ equilibrium}

Genotypes for the 400 Ae. aegypti from Córdoba city can be accessed at https://doi.org/10.6084/m9.figshare.10265630.

In most geographical populations, mean $f$ values were statistically significant according to the Bonferroni correction ( $f$ mean $=0.143$, $\mathrm{ES}=0.054$; Table 1). There was no evidence of scoring errors due 
Table 1. Geographical location and statistics of 20 populations of Aedes aegypti in Cordoba city

\begin{tabular}{|c|c|c|c|c|c|c|c|}
\hline Sampling sites* & Latitude & Longitude & Number of eggs & Ho & $\mathrm{He}$ & $\mathrm{AR}$ & $f$ \\
\hline VCA & -31.379092 & -64.215032 & 408 & 0.49 & 0.61 & 4.09 & 0.23 \\
\hline ARG & -31.343217 & -64.253403 & 306 & 0.57 & 0.71 & 5.43 & 0.23 \\
\hline VRI & -31.316180 & -64.297904 & 452 & 0.77 & 0.72 & 5.65 & -0.04 \\
\hline $\mathrm{CNO}$ & -31.323463 & -6.427762 & 391 & 0.53 & 0.71 & 5.83 & 0.25 \\
\hline MDS & -31.368596 & -64.189410 & 315 & 0.67 & 0.74 & 5.79 & 0.12 \\
\hline GUI & -31.313927 & -64.176594 & 179 & 0.62 & 0.72 & 5.93 & 0.17 \\
\hline GBU & -31.391207 & -64.168302 & 99 & 0.62 & 0.66 & 5.37 & 0.09 \\
\hline SNI & -31.379152 & -64.151052 & 903 & 0.67 & 0.71 & 5.33 & 0.09 \\
\hline PUE & -31.407935 & -64.162907 & 827 & 0.63 & 0.73 & 6.24 & 0.16 \\
\hline SVI & -31.421669 & -64.138973 & 282 & 0.55 & 0.72 & 5.69 & 0.26 \\
\hline SVII & -31.420965 & -64.154130 & 323 & 0.59 & 0.71 & 5.32 & 0.20 \\
\hline ITU & -31.464947 & -64.087328 & 454 & 0.59 & 0.65 & 5.61 & 0.12 \\
\hline JID & -31.455354 & -64.128140 & 273 & 0.66 & 0.76 & 6.20 & 0.16 \\
\hline $\mathrm{COL}$ & -31.481008 & -64.136469 & 317 & 0.62 & 0.75 & 6.27 & 0.20 \\
\hline VLI & -31.475372 & -64.220960 & 338 & 0.62 & 0.71 & 5.81 & 0.16 \\
\hline EFL & -31.449382 & -64.250986 & 440 & 0.53 & 0.53 & 4.21 & 0.04 \\
\hline JAR & -31.444974 & -64.179183 & 373 & 0.55 & 0.63 & 5.46 & 0.16 \\
\hline VUR & -31.391933 & -64.235826 & 1149 & 0.64 & 0.76 & 6.28 & 0.19 \\
\hline LPL & -31.421033 & -64.235523 & 378 & 0.64 & 0.60 & 4.79 & -0.04 \\
\hline OBS & -31.421364 & -64.200737 & 288 & 0.66 & 0.68 & 5.80 & 0.06 \\
\hline
\end{tabular}

$H_{o}$ : observed heterozygosity; $H_{e}$ : expected heterozygosity; AR: allelic richness based on a minimum sample size of 16 individuals; $f$ mean value across 10 loci of the $F_{\mathrm{IS}}$ estimator; underlined values: statistically significant values after the Bonferroni correction $(P<0.001)$.

"VCA (Villa Cabrera), ARG (Argüello), VRI (Villa Rivera Indarte), CNO (Cerro Norte), MDS (Marqués de Sobremonte), GUI (Guiñazú), SNI (San Nicolás), PUE (Pueyrredón), SVI (San Vicente I), ITU (Ituzaingó), JID (José Ignacio Díaz), COL (Coronel Olmedo), VLI (Villa El Libertador), EFL (Estación Flores), VUR (Villa Urquiza), LPL (Los Plátanos), GBU (General Bustos), SVII (San Vicente II), JAR (Jardín), and OBS (Observatorio).

to stuttering or large allele dropouts for any of the loci or populations. The possible presence of null alleles was detected in different loci in some populations, but not in the same locus across samples (Supp Table 2 [online only]). The general probability of linkage between pairs of loci was low, although significant $(6.75 \%, P>0.01)$. However, no pair was observed systematically correlated across populations; therefore, a physical linkage between loci was rejected (Supp Table 3 [online only]).

Across all loci, the AR values ranged from 4.09 to 6.28 (average $\mathrm{AR}=5.56)$ and the average values of $H o$ and $H e$ were 0.61 and 0.69 , respectively. Locus-by-locus $\mathrm{AR}, H_{o}, H_{e}$ and $f$ values are shown in Supp Table 1 [online only].

\section{Population Genetic Structure}

The comparisons between pairs of neighborhoods showed $\theta$ values ranging from 0.002 to 0.285 (mean $=0.081, \mathrm{SE}=0.020$ ). The levels of genetic differentiation were statistically significant in $85.26 \%$ of the comparisons after the Bonferroni correction (Table 2). The isolation by distance test revealed a nonsignificant correlation $(r=-0.098, P=0.292$, Fig. 2$)$ between normalized genetic and geographical distances between pairs of neighborhoods.

In the Bayesian analysis with STRUCTURE, the best $K$ determined by Evanno's $\Delta K$ statistic was $K=2$, with $K=3$ and $K=5$ also showing high $\ln [\operatorname{Pr}(X \mid K)]$ values (Supp Fig. 1 [online only]). For the two clusters solution (Fig. 3a), most of the individuals from VCA, OBS, VUR, and LPL had a high proportion of ancestry in cluster 1, whereas those from EFL in cluster 2. The $K=3$ solution (Fig. 3b) partitioned cluster 1: VCA and VUR from OBS and LPL. In both solutions, the other sampling sites consisted in a mixture of individuals having high $Q$ in one of the two (or three) clusters and admixed ones.

In the DAPC analysis, the best-supported K-means clustering model, identified by the minimum $\mathrm{K}$ value beyond which $\mathrm{BIC}$ changes are negligible, was $K=7$ (Supp Fig. 2a [online only]). The
DAPC clustering was performed by retaining 33 PCs (Supp Fig. 2b [online only]) and 6 discriminant functions. The scatterplot of individuals on the two principal components showed that three clusters (2, 4, and 5) differed markedly from the rest (Fig. 4). Individuals from GBU, PUE, and SVII predominated in Cluster 4. All but one individual from EFL were contained in cluster 2, together with half the individuals of VLI and half of those from GUI. The rest of samples from GUI were grouped in cluster 1. The remaining clusters show a considerably degree of overlapping and contained individuals from several populations. However, individuals from southern neighborhoods predominated in cluster 3 (LPL, OBS, JAR, and ITU), and individuals from north/northwestern neighborhoods in cluster 6 (CNO, ARG, VCA, SNI, and PUE, Supp Fig. 3 [online only]).

\section{Discussion}

\section{$\mathrm{H}-\mathrm{W}$ Equilibrium and Genetic Variability}

When analyzing the genetic structure of natural populations, one of the main objectives is to delimit breeding units in order to identify discrete populations that, in the case of virus vectors, could present differences in insecticide resistance, vector competence, and other attributes of epidemiological interest. With this aim, the first analysis consists of checking if the genotypic frequencies follow a predictable pattern according to the random mating hypothesis. Some of the geographical populations studied in Córdoba City were close to the $H$-W equilibrium (VRI, EFL, LPL, and OBS), whereas others showed an overall heterozygote deficiency (Table 1). Vidal et al. (2012), Rašić et al. (2015), and Wilke et al. (2017) also reported significant homozygote excess in populations of this species from São Paulo and Rio de Janeiro cities (Brazil). Our results could be explained by the presence of null alleles. However, only a few populations exhibited some loci with evidence of null alleles at low frequencies (Supp Table 2 [online only]). Aedes aegypti prefers domestic environments and, 
Table 2. Genetic population differentiation of Aedes aegypti in Cordoba city

\begin{tabular}{|c|c|c|c|c|c|c|c|c|c|c|c|c|c|c|c|c|c|c|c|c|}
\hline te & VCA & ARG & VRI & $\mathrm{CNO}$ & MDS & GUI & GBU & SNI & PUE & SVI & SVII & ITU & JID & COL & VLI & EFL & JAR & VUR & LPL & OBS \\
\hline & - & & & & & & & & & & & & & & & & & & & \\
\hline R & & 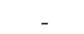 & & & & & & & & & & & & & & & & & & \\
\hline R & & & & & & & & & & & & & & & & & & & & \\
\hline NO & & & & & & & & & & & & & & & & & & & & \\
\hline DS & & & & & - & 0.050 & & & & & & & & & & & & & & \\
\hline UI & & & & & & - & & & & & & & & & & & & & & \\
\hline BU & & $*$ & & & & & - & & & & & & & & & & & & & \\
\hline & $* *$ & $* *$ & & & & & NS & - & & & & & & & & & & & & \\
\hline JE & $* *$ & & & & $* *$ & & & & - & 0.020 & & & & & & & & & & \\
\hline & & & & & & & & & & & 0.048 & & & & & & & & & \\
\hline /II & & $* *$ & & & & & & & NS & & & 0.087 & & & & & & & & 0.107 \\
\hline$\Gamma \mathrm{U}$ & $* *$ & $*$ & & $* *$ & $* *$ & $* *$ & $* *$ & $* *$ & * & $* *$ & $* *$ & - & 0.075 & & & & & & & 0.086 \\
\hline ID & $* *$ & $* *$ & $*$ & NS & $*$ & $*$ & $* *$ & $* *$ & , & $*$ & $* *$ & & - & 0.012 & & & & & & 0.049 \\
\hline $\mathrm{COL}$ & $* *$ & NS & & $* *$ & $* *$ & & $* *$ & $* *$ & & $*$ & $*$ & $* *$ & & - & 0.033 & & & & & 0.066 \\
\hline LI & $* *$ & $* *$ & $* *$ & $* *$ & $*$ & $* *$ & $* *$ & & $* *$ & $*$ & $*$ & $* *$ & NS & & - & 0.093 & & & & \\
\hline $\mathrm{FL}$ & $* *$ & $* *$ & $* *$ & $* *$ & $* *$ & $* *$ & $* *$ & & $* *$ & $* *$ & $*$ & $* *$ & $* *$ & $* *$ & NS & - & 0.205 & & & 0.219 \\
\hline $\mathrm{R}$ & $* *$ & $* *$ & $* *$ & $* *$ & $* *$ & $* *$ & $* *$ & $* *$ & $* *$ & NS & $* *$ & $*$ & $* *$ & $* *$ & $* *$ & $* *$ & - & 0.109 & 0.075 & 0.096 \\
\hline UR & $* *$ & NS & NS & $* *$ & $* *$ & NS & $* *$ & $* *$ & $* *$ & $* *$ & $* *$ & $* *$ & $*$ & NS & $* *$ & $* *$ & $* *$ & - & 0.124 & 0.090 \\
\hline PL & $* *$ & $* *$ & $* *$ & $* *$ & $* *$ & $* *$ & $* *$ & $* *$ & $* *$ & $* *$ & $* *$ & $* *$ & $* *$ & $* *$ & $* *$ & NS & $* *$ & NS & - & 0.080 \\
\hline BS & $* *$ & $* *$ & $* *$ & NS & $* *$ & $* *$ & $* *$ & $* *$ & NS & $* *$ & $* *$ & $* *$ & $* *$ & $* *$ & NS & $* *$ & $* *$ & $* *$ & $* *$ & - \\
\hline
\end{tabular}

Genetic differentiation ( $\Theta$ values) between pairs of sampling sites are shown above the diagonal. Below the diagonal, significance of $\Theta$ after the Bonferroni correction.

NS: nonsignificant value.

"Significant at $\alpha=0.05$

* Significant at $\alpha=0.01$.

in the presence of adequate sites for oviposition and feeding, females usually do not move away from their breeding sites (Russell et al. 2005, Reiter 2007). This short range of active dispersal might determine small breeding units. Consistent with this, several works have estimated low effective population size $\left(N_{e}\right)$, regardless of the level of urban development (Endersby et al. 2011, Olanratmanee et al. 2013, Rašić et al. 2015, Saarman et al. 2017). Within these small units, the likelihood of crosses between related individuals would increase, and therefore, the existence of a certain degree of inbreeding cannot be discarded as another factor contributing to the observed departure from the $H-W$ equilibrium.

Allele richness and mean expected heterozygosities obtained in this work were higher than those reported for several populations from eastern Brazil (Vidal et al. 2012, Monteiro et al. 2014, Rašić et al. 2015, Wilke et al. 2017) and the southern region of the United States (Pless et al. 2017), using different ensembles of the set of microsatellites from Chambers et al. (2007) and Slotman et al. (2007). In Ae. aegypti populations from Argentina, Rondan Dueñas et al. (2009) and Albrieu Llinás and Gardenal (2012) reported a high degree of haplotype diversity in two mitochondrial genes in samples from Córdoba, concluding that the convergence of populations of different genetic composition could explain, at least in part, the variability observed. Because of the central location of Córdoba in the country, a similar explanation could be applied to our present results using microsatellites and would help to explain the high levels of genetic variability, despite the evidence for small breeding units.

\section{Population Genetic Structure}

The levels of genetic differentiation between pairs of populations were statistically significant in $85.26 \%$ of the cases (Table 2) and were random with respect to geographic distance $(r=-0.093$, $P=0.292$ ). Other comparable studies of urban settlements using microsatellites reported high levels of genetic differentiation between

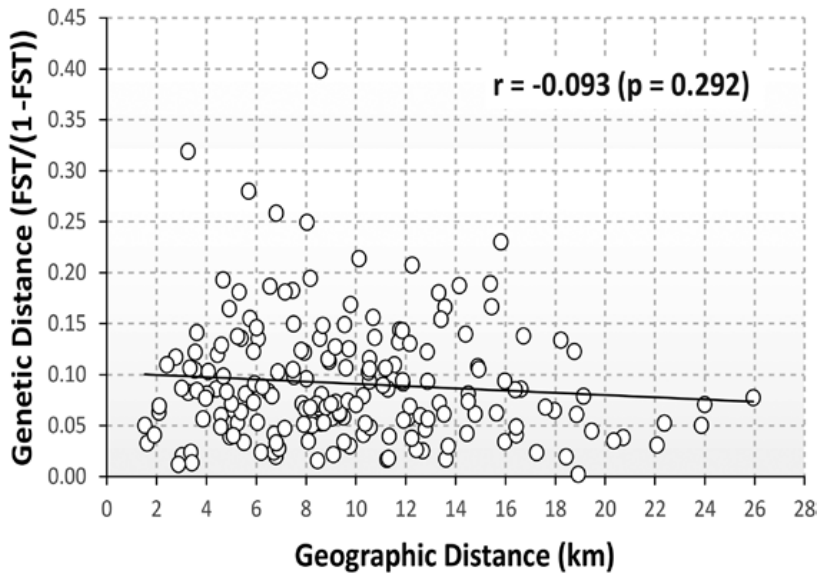

Fig. 2. Genetic isolation by geographical distance. Scatterplot of the linearized genetic distance $\left(F_{\mathrm{ST}} /\left(1-F_{\mathrm{ST}}\right)\right)$ and geographical distance $(\mathrm{km})$ among pairs of neighborhoods using GenalEx (Peakall and Smouse 2012).

Ae. aegypti populations and lack of isolation by distance. A positive correlation between geographic and genetic distances is observed when the populations reach a balance between genetic drift and gene flow. Different factors were invoked as agents producing genetic differentiation and lack of IBD pattern: rainfall seasonality, high temperatures (causing discontinuity in the water volume of small reservoirs for oviposition) and the periodic application of insecticides, which would originate population bottlenecks, resulting in several independent genetic drift effects that could randomly preserve different combinations of alleles in each population (e.g., Ocampo and Wesson 2004, Paupy et al. 2004, Olanratmanee et al. 2013, Wilke et al. 2017). Wilke et al. (2017) also suggested that, given that breeding sites are widely available in cities, females do 


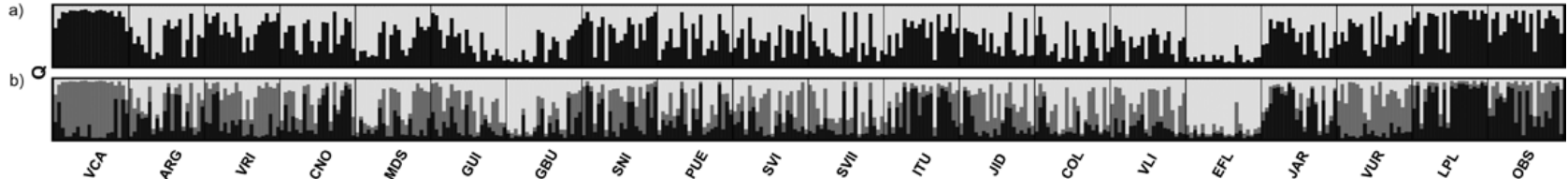

Fig. 3. Genetic structure of Aedes aegypti inferred from STRUCTURE analysis based on 10 microsatellite loci. Each individual is represented by a vertical bar divided into sections proportional to its membership $(Q)$ to each inferred cluster. (a) $K=2$, black: cluster 1 , white: cluster 2 ; (b) $K=3$, black: cluster 1 , gray: cluster 2, white: cluster 3.

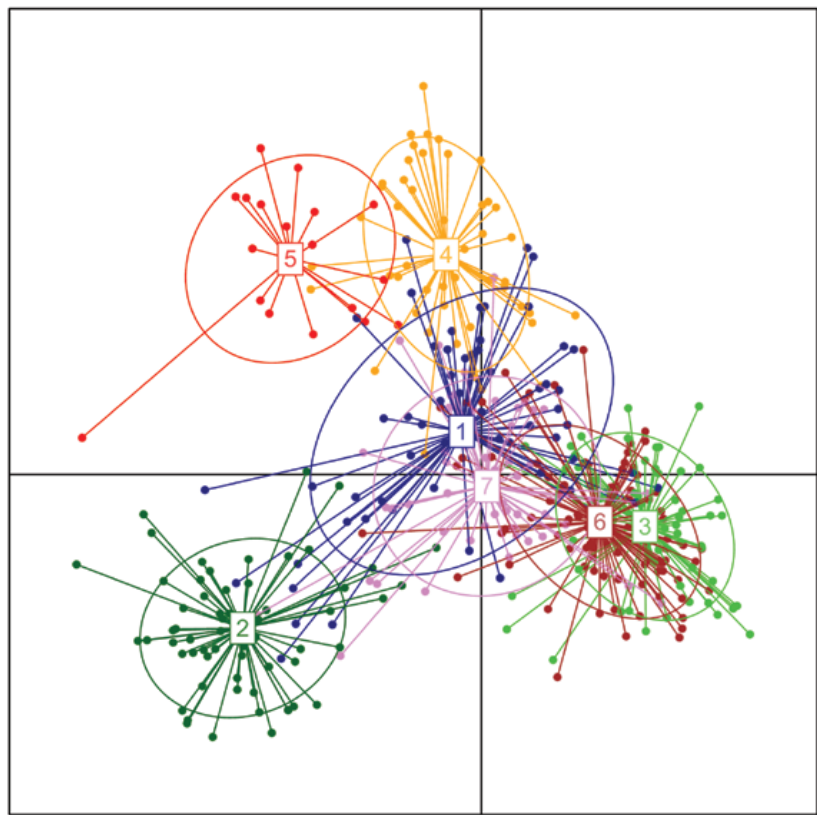

Fig. 4. Multivariate clustering of Aedes aegypti obtained with the DAPC method. Clustering was performed using Adegenet (Jombart 2008). The best supported solution was for $K=7$.

not have to actively seek hosts or breeding sites, discouraging dispersal and which would, in turn, avoid the establishment of an IBD pattern. Besides the within-populations factors discussed above, the establishment of new stocks from bordering countries through passive transport has continued steadily after the first re-introduction of Ae. aegypti in Argentina in 1986 (Rondán-Dueñas et al. 2009) and this process would have also prevented the populations from achieving the genetic drift-gene flow balance. Another possible cause of the lack of IBD would be micro-geographic local adaptation in Ae. aegypti populations from Córdoba city. However, our current data provide no direct evidence of such process in our study sites.

The Bayesian and multivariate clustering analyses indicated genetic structuring of populations in Córdoba city. Two genetic clusters were detected with STRUCTURE and seven with DAPC. We must consider that the DAPC approach seeks synthetic variables (the discriminant functions), which reflect differences between groups as best as possible, while minimizing variation within clusters. Unlike DAPC, the Bayesian approach infers the most probable $K$ by maximizing $H-W$ equilibrium within clusters. However, both methods revealed similar trends. Some populations within the city tend to show genetic distinctiveness (like GBU, LPL, OBS, EFL, VUR, and VCA), whereas others present different levels of admixture. In addition, all populations include individuals with high membership in their population, and others highly admixed or with membership in another cluster. The close genetic relationship among geographically distant individuals could be the result of passive transport of eggs, larvae, or adults, since these distances are far beyond the maximum active dispersal distance observed for the species. Moreover, previous works on a wider geographical scale also demonstrated the influence of the passive dispersal of Ae. aegypti on its population genetic structure both in Argentina (Julio et al. 2009; Rondan Dueñas et al. 2009; Soliani et al. 2010; Albrieu Llinás and Gardenal 2011, 2012; DíazNieto et al, 2016) and in other parts of the world (Huber et al. 2004, Guagliardo et al. 2019).

The VCA neighborhood presented the lowest AR values (Table 1) and differed genetically from all the other sites with the classical $F$ approach (Table 2). In DAPC, it is the only population with a considerable proportion of their individuals in cluster 7 and in STRUCTURE $(K=3)$ almost all of its individuals show high membership to cluster 2 (Fig. 3b). During the re-introduction of Ae. aegypti in Córdoba province, one of the first records of the species was documented in this neighborhood (Almirón and Ludueña-Almeida 1998). Accordingly, two hypotheses may be assumed: first, that the individuals sampled in this site are representatives of a small initial foreign population, and second, that to deal with this first detection, an important vector control campaign was conducted in the area. The different genetic constitution and low polymorphism level detected here would be a consequence of an initial founder effect, i.e., the loss of genetic variation that occurs when a new population is established by a minimal number of individuals, which was reinforced by a subsequent bottleneck event generated during the drastic reduction of the vector population in this site.

\section{Final Considerations}

The knowledge of population genetic structure provides critical information for the implementation of alternative control strategies (McCoy 2008) like the introduction of sterile adult mosquitoes to natural vector populations (Wilke et al. 2009) and/or the treatment of larvae with insect growth regulators (Ahmed and Vogel 2016), since it will indicate the potential range of spread/effectiveness of the treatment.

Several studies documented that the susceptibility to arboviruses infection (Tabachnick 2013), the efficiency of disease transmission (Failloux et al. 2002), and insecticide resistance (Faucon et al. 2015) depend on the genetic and geographical background of mosquito populations (Faucon et al. 2015). High levels of genetic diversity and the admixed ancestry detected in some individuals in almost all neighborhoods of Córdoba city would be an indicator of a confluence of individuals from different geographical sources, which could also imply polymorphism in the viral susceptibility, vector competence or resistance to insecticides.

Regarding control programs, in the presence of a fever case in a neighborhood with low admixed ancestry, a focal treatment both in the patient's home and in his immediate environment is, in fact, a 
useful tool to control the spread of the disease. However, if the detection of a fever case occurs in a highly admixed neighborhood, i.e., with multiple contributions of different genetic pools, more complex measures would be necessary to prevent the virus propagation.

\section{Supplementary Data}

Supplementary data are available at Journal of Medical Entomology online.

\section{Acknowledgments}

All ovitraps were weekly replaced by personnel of the CIEC (Centro de Investigaciones Entomológicas de Córdoba) and of the Dirección de Epidemiología del Ministerio de Salud de la Provincia de Córdoba, under the Ae. aegypti entomological monitoring program initiated in 2009. We thank Paolo Daniel Sartor for his collaboration during the larval rearing stage. This study was supported by grants from Consejo Nacional de Investigaciones Científicas y Técnicas (CONICET, PIP 11220150100474CO), Agencia Nacional de Promoción Científica y Tecnológica (ANPCyT, MINCyT, PICT2016 N $\mathrm{N}^{\circ}$ 1328) and Fondo para la Investigación Científica y Tecnológica (FONCYT, PID 05/I413). M. B. C., W. R. A. and C. N. G. are career researchers of CONICET; A. M. A. is Fellow of the same institution.

\section{References Cited}

Ahmed, M. A., and C. F. Vogel. 2016. The role of octopamine receptor agonists in the synergistic toxicity of certain insect growth regulators (IGRs) in controlling Dengue vector Aedes aegypti (Diptera: Culicidae) mosquito. Acta Trop. 155: 1-5.

Alberto, F. 2009. MsatAllele_1.0: an R package to visualize the binning of microsatellite alleles. J. Hered. 100: 394-397.

Albrieu Llinás, G., and C.N. Gardenal. 2011. Introduction of different lineages of Aedes aegypti in Argentina. J. Am. Mosquito Control Assoc. 27: 429-432.

Albrieu Llinás, G., and C.N. Gardenal. 2012. Phylogeography of Aedes aegypti in Argentina: long-distance colonization and rapid restoration of fragmented relicts after a continental control campaign. Vector-Borne Zoonotic Dis. 12: 254-261.

Almirón, W.R., and F. Ludueña-Almeida. 1998. Aedes aegypti (Diptera: Culicidae) en Córdoba, Argentina. Rev. Soc. Entomol. Argent. 57: 1-4.

Ballinger-Crabtree, M. E., W. C. Black, 4th, and B. R. Miller. 1992. Use of genetic polymorphisms detected by the random-amplified polymorphic DNA polymerase chain reaction (RAPD-PCR) for differentiation and identification of Aedes aegypti subspecies and populations. Am. J. Trop. Med. Hyg. 47: 893-901.

Broquet, T., and E. J. Petit. 2009. Molecular estimation of dispersal for ecology and population genetics. Annu. Rev. Ecol. Evol. Syst. 40: 193-216.

Chambers, E. W., J. K. Meece, J. A. McGowan, D. D. Lovin, R. R. Hemme, D. D. Chadee, K. McAbee, S. E. Brown, D. L. Knudson, and D. W. Severson. 2007. Microsatellite isolation and linkage group identification in the yellow fever mosquito Aedes aegypti. J. Hered. 98: 202-210.

da Costa-Fraga, E., J.M. dos Santos, and J. de Freitas-Maia. 2003. Enzymatic variability in Aedes aegypti (Diptera: Culicidae) populations from Manaus-AM, Brazil. Genet. Mol. Biol. 26: 181-187.

Curto, S.I., R. Boffi, A.E. Carbajo, R. Plastina, N. Schweigmann, and O.D. Salomón. 2002. Reinfestación del territorio argentino por Aedes aegypti. Distribución geográfica (1994-1999), pp. 127-137. In O. D. Salomón (ed.) Actualizaciones en Artropología Sanitaria Argentina, Fundación Mundo Sano, Buenos Aires, Argentina.

Díaz-Nieto, L. M., M. B. Chiappero, C. Díaz de Astarloa, A. Maciá, C. N. Gardenal, and C. M. Berón. 2016. Genetic evidence of expansion by passive transport of Aedes (Stegomyia) aegypti in Eastern Argentina. PLoS Negl. Trop. Dis. 10: e0004839.

Domínguez, C. and S. Lagos. 2001. Presencia de Aedes aegypti (Diptera: Culicidae) en la provincia de Mendoza, Argentina. Rev. Soc. Entomol. Argent. 60: 79-80.
Earl, D.A. and B.M. Von Holdt. 2012. STRUCTURE HARVESTER: a website and program for visualizing STRUCTURE output and implementing the Evanno method. Conserv. Genet. Resour. 4: 359-361.

El Mousadik, A., and R. J. Petit. 1996. High level of genetic differentiation for allelic richness among populations of the argan tree [Argania spinosa (L.) Skeels] endemic to Morocco. Theor. Appl. Genet. 92: 832-839.

Endersby, N. M., A. A. Hoffmann, V. L. White, S. A. Ritchie, P. H. Johnson, and A. R. Weeks. 2011. Changes in the genetic structure of Aedes aegypti (Diptera: Culicidae) populations in Queensland, Australia, across two seasons: implications for potential mosquito releases. J. Med. Entomol. 48: 999-1007.

Evanno, G., S. Regnaut, and J. Goudet. 2005. Detecting the number of clusters of individuals using the software STRUCTURE: a simulation study. Mol. Ecol. 14: 2611-2620.

Failloux, A. B., M. Vazeille, and F. Rodhain. 2002. Geographic genetic variation in populations of the dengue virus vector Aedes aegypti. J. Mol. Evol. 55: 653-663.

Faucon, F., I. Dusfour, T. Gaude, V. Navratil, F. Boyer, F. Chandre, P. Sirisopa, K. Thanispong, W. Juntarajumnong, R. Poupardin, et al. 2015. Identifying genomic changes associated with insecticide resistance in the dengue mosquito Aedes aegypti by deep targeted sequencing. Genome Res. 25: 1347-1359.

Goudet, J. 2002. FSTAT, a program to estimate and test gene diversities and fixation indices (version 2.9.3). Available from http://www.unil.ch/izea/ softwares/fstat.html. Updated from Goudet (1995).

Grech, M., A. Visintin, M. Laurito, E. Estallo, P. Lorenzo, I. Roccia, M. Korin, F. Goya, F. Ludueña-Almeida, and W. Almirón. 2012. New records of mosquito species (Diptera: Culicidae) from Neuquén and La Rioja provinces, Argentina. Rev. Saude Publica. 46: 387-389.

Guagliardo, S. A. J., Y. Lee, A. A. Pierce, J. Wong, Y. Y. Chu, A. C. Morrison, H. Astete, B. Brosi, G. Vazquez-Prokopec, T. W. Scott, et al. 2019. The genetic structure of Aedes aegypti populations is driven by boat traffic in the Peruvian Amazon. PLoS Negl. Trop. Dis. 13: e0007552.

Gubler, D.J. 2014. Dengue viruses: their evolution, history and emergence as a global public health problem. In D. J. Gubler, E. E. Ooi, J. Farrar and S. Vasudevan (eds.), Dengue and dengue haemorrhagic fever, Second Edition, C.A.B. International, London, United Kingdom.

Higgs, S., and D. Vanlandingham. 2015. Chikungunya virus and its mosquito vectors. Vector Borne Zoonotic Dis. 15: 231-240.

Huber, K., L. Le Loan, T. H. Hoang, S. Ravel, F. Rodhain, and A. B. Failloux. 2002. Genetic differentiation of the dengue vector, Aedes aegypti (Ho Chi Minh City, Vietnam) using microsatellite markers. Mol. Ecol. 11: 1629-1635.

Huber, K., L. L. Loan, N. Chantha, and A. B. Failloux. 2004. Human transportation influences Aedes aegypti gene flow in Southeast Asia. Acta Trop. 90: 23-29.

Jakobsson, M., and N. A. Rosenberg. 2007. CLUMPP: a cluster matching and permutation program for dealing with label switching and multimodality in analysis of population structure. Bioinformatics. 23: 1801-1806.

Jombart, T. 2008. adegenet: a R package for the multivariate analysis of genetic markers. Bioinformatics. 24: 1403-1405.

Jombart, T., S. Devillard, and F. Balloux. 2010. Discriminant analysis of principal components: a new method for the analysis of genetically structured populations. BMC Genet. 11: 94.

Julio, N. B., M. B. Chiappero, H. J. Rossi, J. C. Rondan Dueñas, and C. N. Gardenal. 2009. Genetic structure of Aedes aegypti in the city of Córdoba (Argentina), a recently reinfested area. Mem. Inst. Oswaldo Cruz. 104: 626-631.

Kumar, N.S., and G. Gurusubramanian. 2011. Random amplified polymorphic DNA (RAPD) markers and its applications. Sci. Vis. 11: 116-124.

Mayer, S. V., R. B. Tesh, and N. Vasilakis. 2017. The emergence of arthropodborne viral diseases: a global prospective on dengue, chikungunya and zika fevers. Acta Trop. 166: 155-163.

McCoy, K. D. 2008. The population genetic structure of vectors and our understanding of disease epidemiology. Parasite. 15: 444-448.

Monteiro, F. A., R. Schama, R. Shama, A. J. Martins, A. Gloria-Soria, J. E. Brown, and J. R. Powell. 2014. Genetic diversity of Brazilian Aedes 
aegypti: patterns following an eradication program. Plos Negl. Trop. Dis. 8: e3167.

Mousson, L., M. Vazeille, S. Chawprom, S. Prajakwong, F. Rodhain, and A. B. Failloux. 2002. Genetic structure of Aedes aegypti populations in Chiang Mai (Thailand) and relation with dengue transmission. Trop. Med. Int. Health. 7: 865-872.

Ocampo, C. B., and D. M. Wesson. 2004. Population dynamics of Aedes aegypti from a dengue hyperendemic urban setting in Colombia. Am. J. Trop. Med. Hyg. 71: 506-513.

Olanratmanee, P., P. Kittayapong, C. Chansang, A. A. Hoffmann, A. R. Weeks, and N. M. Endersby. 2013. Population genetic structure of Aedes (Stegomyia) aegypti (L.) at a micro-spatial scale in Thailand: implications for a dengue suppression strategy. PLoS Negl. Trop. Dis. 7: e1913.

Paupy, C., N. Chantha, K. Huber, N. Lecoz, J. M. Reynes, F. Rodhain, and A. B. Failloux. 2004. Influence of breeding sites features on genetic differentiation of Aedes aegypti populations analyzed on a local scale in Phnom Penh Municipality of Cambodia. Am. J. Trop. Med. Hyg. 71: 73-81.

Peakall, R., and P. E. Smouse. 2012. GenAlEx 6.5: genetic analysis in Excel. Population genetic software for teaching and research-an update. Bioinformatics. 28: 2537-2539.

Pless, E., A. Gloria-Soria, B. R. Evans, V. Kramer, B. G. Bolling, W. J. Tabachnick, and J. R. Powell. 2017. Multiple introductions of the dengue vector, Aedes aegypti, into California. PLoS Negl. Trop. Dis. 11: e0005718.

Powell, J. R., A. Gloria-Soria, and P. Kotsakiozi. 2018. Recent History of Aedes aegypti: vector genomics and epidemiology records. Bioscience. 68: 854-860.

Pritchard, J. K., M. Stephens, and P. Donnelly. 2000. Inference of population structure using multilocus genotype data. Genetics. 155: 945-959.

R Development Core Team. 2007. R: a language and environment for statistical computing. Vienna (Austria): R Foundation for Statistical Computing. Available from: URL http://www.Rproject.org

Rašić, G., R. Schama, R. Powell, R. Maciel-de Freitas, N. M. EndersbyHarshman, I. Filipović, G. Sylvestre, R. C. Máspero, and A. A. Hoffmann. 2015. Contrasting genetic structure between mitochondrial and nuclear markers in the dengue fever mosquito from Rio de Janeiro: implications for vector control. Evol. Appl. 8: 901-915.

Reiter, P. 2007. Oviposition, dispersal, and survival in Aedes aegypti: implications for the efficacy of control strategies. Vector Borne Zoonotic Dis. 7: 261-273

Reiter, P. 2014. Surveillance and control of urban dengue vectors. In D. J. Gubler, E. E. Ooi, J. Farrar and S. Vasudevan (eds.), Dengue and dengue haemorrhagic fever, 2nd edn, C.A.B. International, London, United Kingdom.

Rondan Dueñas, J.C., G. Albrieu Llinás, G.M. Panzetta-Dutari, and C.N. Gardenal. 2009. Two different routes of colonization of Aedes aegypti in Argentina. J. Med. Entomol. 46: 1344-1354.

Rosenberg, N.A. 2004. Distruct: a program for the graphical display of population structure. Mol. Ecol. Notes. 4: 137-138.

Rossi, G.C., and W.R. Almirón. 2004. Clave ilustrada para la identificación de larvas de mosquitos de interés sanitario encontradas en criaderos artificiales en la Argentina. Publicaciones Mundo Sano, Serie Enfermedades Transmisibles 5: 53 .

Rousset, F. 1997. Genetic differentiation and estimation of gene flow from F-statistics under isolation by distance. Genetics. 145: 1219-1228.

Russell, R. C., C. E. Webb, C. R. Williams, and S. A. Ritchie. 2005. Markrelease-recapture study to measure dispersal of the mosquito Aedes aegypti in Cairns, Queensland, Australia. Med. Vet. Entomol. 19: 451-457.

Saarman, N. P., A. Gloria-Soria, E. C. Anderson, B. R. Evans, E. Pless, L. V. Cosme, C. Gonzalez-Acosta, B. Kamgang, D. M. Wesson, and J. R. Powell. 2017. Effective population sizes of a major vector of human diseases, Aedes aegypti. Evol. Appl. 10: 1031-1039.

Schweigmann, N., and R. Bofi. 1998. Aedes aegypti y Aedes albopictus: situación entomológica de la Región, pp. 259-263. In A.C. Seijo, O.P. Iarghi, M.O. Espinosa (eds.), Temas de zoonosis y enfermedades emergentes, Asociación Argentina de Zoonosis, Buenos Aires, Argentina.

Slotman, M.A., N.B. Kelly, L.C. Harrington, S. Kitthawee, J.W. Jones, T.W. Scott, A. Caccone, and J.R. Powell. 2007. Polymorphic microsatellite markers for studies of Aedes aegypti (Diptera: Culicidae), the vector of dengue and yellow fever. Mol. Ecol. Res. 7: 168-171.

Soliani, C., J. Rondan-Dueñas, M. B. Chiappero, M. Martínez, E. G. Da Rosa, and C. N. Gardenal. 2010. Genetic relationships among populations of Aedes aegypti from Uruguay and northeastern Argentina inferred from ISSR-PCR data. Med. Vet. Entomol. 24: 316-323.

de Sousa, G. B., A. Blanco, and C. N. Gardenal. 2001. Genetic relationships among Aedes aegypti (Diptera: Culicidae) populations from Argentina using random amplified polymorphic DNA polymerase chain reaction markers. J. Med. Entomol. 38: 371-375.

Tabachnick, W. J. 2013. Nature, nurture and evolution of intra-species variation in mosquito arbovirus transmission competence. Int. J. Environ. Res. Public Health. 10: 249-277.

Van Oosterhout C., W.F. Hutchinson, D.P. Wills, and P. Shipley. 2004. MICRO-CHECKER: software for identifying and correcting genotyping errors in microsatellite data. Mol. Ecol. Notes. 4: 535-538.

Vidal, P. O., and L. Suesdek. 2012. Comparison of wing geometry data and genetic data for assessing the population structure of Aedes aegypti. Infect. Genet. Evol. 12: 591-596.

Weir, B. S., and C. C. Cockerham. 1984. Estimating F-statistics for the analysis of population structure. Evolution. 38: 1358-1370.

Wilke, A.B., D.D. Nimmo, O. St John, BB Kojin, M.L. Capurro, and M.T. Marrelli. 2009. Mini-review: genetic enhancements to the sterile insect technique to control mosquito populations. AsPac. J. Mol. Biol. Biotechnol. 17: 65-74.

Wilke, A. B. B., R. Wilk-da-Silva, and M. T. Marrelli. 2017. Microgeographic population structuring of Aedes aegypti (Diptera: Culicidae). PLoS One. 12: $\mathrm{e} 0185150$.

Zanotti, G., M. S. De Majo, I. Alem, N. Schweigmann, R. E. Campos, and S. Fischer. 2015. New records of Aedes aegypti at the southern limit of its distribution in Buenos Aires province, Argentina. J. Vector Ecol. 40: 408-411. 